\title{
Comportamento turístico dos visitantes do Parque Nacional da Serra da Capivara
}

\author{
Tourist behavior of visitors of the National Park Serra da Capivara
}

\section{Rafael Fernandes de Mesquita}

Universidade de Fortaleza, Programa de Pós-Graduação em Administração de Empresas, Av. Washington Soares, 1321, Edson Queiroz, CEP 60811-905, Fortaleza, Brazil, fernandesrafael@live.com

\section{Laelson Rochelle Milanês Sousa}

Universidade Federal do Piauí, Programa de Pós-Graduação em Enfermagem, CEP: 64049-550, Teresina, Brazil, laelson_@hotmail.com

\section{Fátima Regina Ney Matos}

Universidade de Fortaleza, Programa de Pós-Graduação em Administração de Empresas, CEP 60811-905, Fortaleza, Brazil, fneymatos@unifor.br

\section{Ana Luiza Almeida do Monte}

Universidade de Fortaleza, Programa de Pós-Graduação em Administração de Empresas, CEP 60811-905, Fortaleza, Brazil, analuiza.monte@gmail.com

\section{Resumo}

A atividade cultural é uma modalidade de atividade turística relativamente recente, desenvolvida com finalidades mercadológicas a partir das últimas décadas do século XX e que gera receitas financeiras e desenvolvimento socioeconômico para diversos locais do globo terrestre. 0 presente trabalho tem como objetivo analisar o comportamento turístico do visitante do Parque Nacional da Serra da Capivara, em São Raimundo Nonato, cidade situada no nordeste brasileiro, avaliando as variáveis de motivação, satisfação, imagem, fontes de informação e comportamento futuro. Para a consecução do objetivo foram aplicados 217 questionários com pessoas que já conheciam o parque e realizadas análises univariadas e testes de regressão linear. Os resultados apontam fragilidade nas fontes de divulgação sobre este destino turístico e ótimas avaliações de sua imagem. A regressão linear demonstrou médio poder de explicação para o cenário em que a satisfação possuía efeito significativo sobre as demais variáveis.

Palavras-chave: Turismo cultural, intenções, motivações, satisfação, Parque Nacional da Serra da Capivara.

\begin{abstract}
Cultural activities is a relatively new type of tourist activity, developed with marketing purposes from the last decades of the twentieth century and that generates income and socioeconomic development to locations across the globe. This study aims to analyze the behavior of tourist visitor on Serra da Capivara National Park in São Raimundo Nonato, a city in Brazilian northeast, assessing the variables of motivation, satisfaction, image, information sources and future behavior. To achieve the objective, 217 questionnaires were applied to people who already knew the park, after the data collection univariate analyzes and linear regression tests were applied. The results indicate the sources of fragility disclosure on this tourist destination and great evaluations of its image. Linear regression showed average explanatory power for the scenario in which the satisfaction had significant effect on the other variables.
\end{abstract}

Keywords: Cultural tourism, intentions, motivations, satisfaction, Serra da Capivara National Park.

\section{Introdução}

O Parque Nacional da Serra da Capivara (Serra da Capivara National Park) foi criado no ano de 1979 como uma forma de proteção aos mais de 900 sítios arqueológicos encontrados na região (Pessis \& Guidon, 2007). Localizado na cidade de São Raimundo Nonato, no Piauí, estado da região nordeste do Brasil, o parque foi incluído no ano de 1991 na lista de Patrimônios Mundiais da UNESCO UNESCO World Heritage Sites, devido a sua relevância histórica para o estudo do desenvolvimento da raça humana.

Situado em área protegida pelo governo federal, o parque possui significativa relevância histórica, cultural e educativa, especialmente creditadas aos registros de presença humana que remontam há mais de 50.000 mil anos (Oliveira Filho \& Monteiro, 2009). São Raimundo Nonato é um destino turístico brasileiro que atrai pessoas de diversos estados do país, bem como visitantes internacionais, para realizarem pesquisas arqueológicas em seus sítios ou para conhecer o Parque Nacional e o Museu do Homem Americano, ambos localizados na cidade (Aguiar \& Carvalho, 2012).

As intenções de visita à cidade como um destino turístico convertem-se em receitas financeiras à medida que pessoas de diversas localidades visitam seus espaços e consomem produtos e serviços (Aguiar \& Carvalho, 2012). Tais receitas se tornam uma importante fonte para o desenvolvimento local (Kuvan \& Perran, 2005) e contribuem para que cidades distantes dos grandes centros comerciais ou regiões metropolitanas consigam manter-se e evoluir com os recursos culturais que possuem.

A dimensão cultural do turismo envolve diversas práticas dos interessados em atividades turísticas, principalmente a visita a locais históricos, sítios arqueológicos, museus e demais lugares que possibilitem experiências de conhecimento e participação na história do patrimônio que desejam frequentar (Ferreira, 2013). Desta forma, a cidade de São Raimundo Nonato torna-se uma fonte para práticas 
que proporcionem tais experiências, além de outras possibilidades, como o Ecoturismo (Oliveira Filho \& Monteiro, 2009).

Assim, dado o contexto e relevância da cidade e do parque, o problema de pesquisa que norteou o presente trabalho foi: quais são as variáveis explicativas do comportamento do turista que visita São Raimundo Nonato em relação à cidade e seus produtos e serviços culturais? Para responder a este questionamento tornou-se necessário conhecer a realidade local em aspectos geográficos e socioeconômicos, contextualizando-a como um destino turístico, e o que os trabalhos acadêmicos dizem a seu respeito. Neste sentido, o Parque Nacional da Serra da Capivara, o Museu do Homem Americano e as demais atrações culturais da cidade são vistas como um aglomerado turístico representado pela própria cidade. Para fins de compreensão, o questionário foi assim direcionado à cidade como um todo.

0 objetivo geral deste trabalho foi investigar as variáveis explicativas da motivação, satisfação, imagem, fontes de informação e intenções de comportamento futuro do turista que visitou São Raimundo Nonato, utilizando-se uma escala com as mesmas finalidades, mas aplicada em Guimarães Capital Europeia da Cultura 2012 (Ferreira, 2013). Foram aplicados questionários com alunos de graduação das mais diversas áreas de conhecimento, buscando-se a maior amostra possível de pessoas que já visitaram o local.

O presente trabalho está estruturado da seguinte forma: apresenta-se o referencial teórico com uma seção inicial sobre turismo cultural, características da cidade de São Raimundo Nonato, o Parque Nacional da Serra da Capivara e outra seção sobre os aspectos metodológicos que caracterizam este trabalho de pesquisa. Em seguida são apresentadas a análise dos resultados e as principais conclusões.

\section{Turismo cultural}

A construção do significado da expressão "turismo cultural" é iniciada quando o turismo percorre caminhos que buscam a cultura de um determinado povo, manifestações artísticas ou ainda artefatos de uma cultura, portanto uma busca de conhecimento mediante contato mais próximo com o comportamento cultural (Batista, 2005). Pode inclusive ser uma alternativa aos destinos ditos turísticos mais convencionais, como localidades à beira do mar e climas ensolarados (Pérez, 2009).

As atividades turísticas de modo geral são ferramentas eficientes no aprimoramento do desenvolvimento econômico e social locais e o turismo cultural é um dos segmentos com maior crescimento e valor agregado (Oliveira Filho \& Monteiro, 2009). Porém, a cultura aliada ao turismo encontra obstáculos no Brasil, pois os investimentos nestes setores específicos são restritos e, para Ferreira (2013), esta modalidade exige uma demanda maior de produtos para que o visitante tenha opções de escolha, cabendo às entidades públicas e privadas impulsionar estas atividades.

0 turismo e a cultura foram as duas atividades mais rentáveis do século XX e a combinação destes dois setores de atividades tornou-se a mais desejável opção de desenvolvimento para muitos países no início do século XXI (Richards, 2010). Entende-se que turismo cultural é o acesso ao comportamento do cotidiano de um povo, à história, comportamento, crenças. 0 turismo cultural não tem o objetivo específico de buscar lazer, apesar de tê-lo como um objetivo secundário, mas o conhecimento em profundidade qualitativa do comportamento cultural e histórico de um determinado povo. Desta forma, o lazer das acomodações são postos em segundo plano e o turista é motivado em conhecer regiões onde a cultura é profundamente respeitada (Moletta, 1998).

Outro ponto a ser evidenciado é o fato de o turismo cultural ser uma modalidade relativamente recente de mercado, pois os passeios com esta finalidade foram gradativamente desenvolvendo-se durante as últimas décadas, principalmente devido às mudanças da natureza do consumo para a sociedade contemporânea, dos fatores de produção e do turismo como um todo (Richards, 2010). 0 turismo cultural estabelece relação muito intima com a vida da comunidade que se tornou destino turístico, para a escolha adequada de um local para se conhecer a fundo determinada cultura é necessário prudência, pois existem lugares que se especializam no turismo a ponto de massificarem as manifestações culturais apenas para garantir um fluxo adequado de turistas (Batista, 2005).

Quando este fato acontece, a cultura é descaracterizada pela própria comunidade que busca intensificar suas manifestações culturais que passam a correr o risco de perder sua identidade cultural que deveria ser espontânea. A implementação e adequação do turismo cultural para finalidades mercadológicas deve ocorrer de forma ordenada e com cautela valorizando os comportamentos locais. Não se deve criar nem inventar atrações voltadas para o público de turistas para que não se perca a identidade local (Batista, 2005). Apesar de a atividade turística apoiar economicamente a localidade de seu entorno, tanto os visitantes quanto os residentes (Calvo-Moura, BerbelPineda, Períañez \& Suárez, 2011), é necessária cautela para providenciar os ajustes adequados ao patrimônio cultural para torná-lo acessível aos interessados.

A relação entre turismo e cultura deve estar bem alinhada à comunidade, valorizando o ambiente e os valores locais (Oliveira, Silva \& Moreira, 2009). 0 turismo cultural corre o risco de cair na descaracterização da cultura local e sofrer influencias de outras culturas. A cultura local deve ser fortalecida para o estabelecimento de rotas turísticas atraídas por manifestações locais (Batista, 2005).

Esse tipo especial de turismo apresenta características peculiares que se diferem dos demais estilos, a primeira característica que merece destaque é o nível de educação ou formação profissional do público que o pratica (Rodríguez \& Abdul-Jalbar, 2012). Observa-se que são pessoas que possuem nível intelectual elevado, a maioria possui curso superior e falam ou compreendem mais de uma língua. Tais especificidades criam um perfil intelectual do público que busca o turismo cultural. São pessoas que buscam níveis superiores de satisfação ao satisfazerem suas necessidades vitais (Rodríguez \& Abdul-Jalbar, 2012). 
A educação é a base paro o desenvolvimento do turismo, especialmente o turismo cultural. 0 grau de educação está diretamente associado aos altos níveis de renda, essa mesma proporção está ligada ao turismo, pois pessoas com maiores rendas viajam mais que as que possuem rendas menores (Batista, 2005). Além disso, a internet influencia na decisão de qual destino deverá ser o escolhido (Sousa, 2014), a família e sua interação com os filhos também apresentam poder de influência (Tiago \& Tiago, 2013) e, principalmente, as fontes de informação que o visitante possui e suas experiências turísticas anteriores (Moreno, Molina \& Moreno, 2013).

Para desenvolver a lealdade deste visitante turístico Kitterlin \& Yoo (2014) propõem que as estratégias de marketing devem ser voltadas ao público específico que frequenta a atração, se local ou não local, dadas as especificidades de cada um. Outros fatores também são relevantes neste processo de fidelização e atração, a qualidade do serviço oferecido e o modo como a gestão do ambiente lida com reclamações, o comprometimento afetivo, a satisfação, o preço adequado e a imagem do local (Batista, Couto, Botelho \& Faias, 2014).

\section{A Cidade de São Raimundo Nonato}

São Raimundo Nonato é um município do estado do Piauí, um dos estados componentes da região Nordeste do Brasil. A cidade se localiza na região sudeste do estado e faz fronteira com os seguintes municípios: Brejo do Piauí, João Costa, Fartura do Piauí, Dirceu Arcoverde, Coronel José Dias, São Lourenço do Piauí, São Braz do Piauí, Bonfim do Piauí e Várzea Branca. Dispõe de uma área de $2.428 \mathrm{~km}^{2}$.

Quanto às atividades econômicas desenvolvidas no município, merece destaque o comércio varejista, pois 329 estabelecimentos são cadastrados com CNPJ e alvará de funcionamento. Sobressaem-se as vendas de produtos que atendem às necessidades vitais, como alimento e vestuário. Entre os municípios vizinhos estabeleceu-se uma microrregião onde São Raimundo Nonato é o Centro de referencia para os demais municípios, portanto torna-se o centro comercial da microrregião.

Entre os estabelecimentos comerciais formalmente cadastrados e com alvará de funcionamento, três são classificadas como lojas que vendem produtos artesanais, estabelecimentos que comercializam produtos que retratam a cultura dos povos das cavernas que ali viveram a milhares de anos e deixaram seu legado nas paredes de pedras, as pinturas rupestres (Oliveira Filho \& Monteiro, 2009). Destaca-se a agricultura de subsistência e criação de animais, pois só a partir de 1990 é que a prática do turismo ganha força na região com a abertura do Parque Nacional Serra da Capivara.

\subsection{Breve descritivo do Parque Nacional da Serra da Capivara}

O Parque Nacional Serra da Capivara é uma área que compreende 129.140 hectares. Por ser bastante extenso, o parque não se limita unicamente à região geográfica e política de São Raimundo Nonato, estendendo-se por Brejo do Piauí, Coronel José Dias, João Costa e São Raimundo Nonato.

Conforme a FUMDHAM (2014) o Parque é intensamente heterogêneo quanto às formações geológicas, concentra a maior parte da arte pré-histórica dos primeiros povos que habitaram as Américas, tais riquezas foram reconhecidas como Patrimônio Natural da Humanidade pela UNESCO. Conta com aproximadamente 900 sítios arqueológicos que juntos somam mais de 40.000 pinturas rupestres. Segundo afirmações da pesquisadora que lidera as investigações no Parque, Niède Guidon, tais vestígios caracterizam a presença humana na região há mais de 50.000 anos, o que vai de encontro a muitas teorias de mainstream para a área da arqueologia sobre a povoação das Américas (Oliveira Filho \& Monteiro, 2009).

Em 2006 o Ministério do Turismo informou sobre a capacidade do Parque para receber turistas: dois milhões de turistas por ano, pois o parque dispõe de infraestrutura com acesso a cento e vinte e oito sítios arqueológicos (Brasil, 2006). Sua estrutura física é composta por guaritas, guardas permanentes, rádios, toaletes, centro de visitantes, auditório e lanchonete. Quanto ao acesso tem-se $300 \mathrm{~km}$ de trilhas carroçáveis e aproximadamente $100 \mathrm{~km}$ para pedestres ainda conta com placas sinalizadoras pelos circuitos. Quanto aos recursos humanos dispõe de 35 condutores turísticos (Oliveira Filho \& Monteiro, 2009). Em relação à acessibilidade, aspecto importante para o bom funcionamento do parque, Carvalho (2012) evidenciou que há algumas adaptações superficiais e que atendem apenas cadeirantes.

\section{Aspectos metodológicos}

O delineamento da pesquisa condiciona o escopo, as técnicas e os métodos que serão utilizados de forma a obter as respostas necessárias associadas ao problema proposto (Mesquita et al., 2014). Assim, a pesquisa realizada teve seu caráter descritivo e quantitativo, enquanto buscava compreender o comportamento entre variáveis.

O presente trabalho foi desenvolvido com estudantes universitários, em nível de graduação, de Instituições de Ensino Superior - IES públicas e privadas, na cidade de Teresina, capital do estado do Piauí. A pesquisa foi realizada com 238 indivíduos respondentes, dos quais 217 questionários foram válidos, pois os demais não se apresentavam preenchidos por completo e, então, foram descartados. Utilizou-se como técnica a aplicação de questionários em vários dias dos meses de março e abril de 2014.

0 instrumento foi elaborado com 8 questões que traçavam o perfil sociodemográfico do público respondente, e outras 58 afirmações que fazem parte da escala desenvolvida por Ferreira (2013), mensuradas por respostas do tipo Likert, de cinco pontos, variando de 1 (Discordo Totalmente) a 5 (Concordo Totalmente). Depois de coletados todos os questionários, a análise foi realizada com apoio do software estatístico IBM SPSS Statistics v. 20.0 (Statistical Package for the Social Sciences). 
A escala desenvolvida por Ferreira (2013) foi aplicada em Guimarães Capital Europeia da Cultura no ano de 2012 e trazida ao contexto do Parque Nacional de Serra da Capivara, adaptando-se algumas afirmações usadas no instrumento de coleta de dados. Ambos os casos são eventos culturais de turismo, um sazonal e outro permanente, mas esta proximidade de finalidade possibilitou a replicação. A classificação da própria cidade em notas foi excluída e as perguntas de perfil sociodemográfico foram modificadas. 0 instrumento apresentou-se adequado após teste com dez respondentes.

Os questionários foram aplicados durante o horário normal das aulas com permissão dos professores, que estavam em trabalho, e das instituições de ensino. Os professores e demais alunos que não responderam os questionários permaneceram em sala no momento da aplicação do instrumento de coleta de dados. Todos os respondentes foram voluntários na pesquisa e não houve qualquer identificação pessoal de suas respostas. Permaneceram, assim, anônimos todos que emitiram suas opiniões a respeito do tema investigado.

Foram utilizadas análises descritivas e univariantes para avaliar os dados. Inicialmente, foram verificadas as médias e frequências de resposta para questionamento e afirmação, mantendo os procedimentos de análise utilizados na escala original, sem uso de medianas ou soma das percentagens (Ferreira, 2013). Em seguida, foi realizada uma análise de regressão linear entre as diferentes variáveis do estudo, com cinco testes que traziam como variável dependente, em ordem: motivação, satisfação, imagem, fontes de informação e comportamento futuro, associando-as às demais como variáveis independentes. Para a regressão, foi utilizada a técnica de transformação das somas das médias às diferentes variáveis do estudo. Após tais procedimentos, foram encontrados os resultados que serão apresentados a seguir.

\section{Discussão e análise dos dados}

Nas subseções seguintes serão apresentados os resultados das análises dos dados coletados após tabulação e apreciação da distribuição de frequências e cálculos das médias de cada uma das asserções propostas nas escalas de motivação, satisfação, imagem, fontes de informação e comportamento futuro dos visitantes de São Raimundo Nonato e, consequentemente do Parque Nacional da Serra da Capivara e do Museu do Homem Americano.

\subsection{Análise descritiva dos dados sociodemográficos}

Tal como indica a Tabela 1, o público respondente da pesquisa é predominantemente formado por pessoas que possuíam entre 21 e 30 anos (46,5\%), seguidos por pessoas que estavam na faixa etária entre 18 e 20 anos (25,8\%). No que diz respeito a diferenciação sexual, a maioria foi caracterizada por pessoas de gênero masculino (58,5\%). A heterogeneidade da amostra não foi intencional, pois foram selecionados sujeitos por disponibilidade para responder ao questionário e o critério de inclusão foi a visita à cidade de São Raimundo Nonato. Somente participaram do estudo pessoas que já haviam realizado passeio turístico ao Parque Nacional da Serra da Capivara.
Tabela 1 - Dados Sociodemográficos

\begin{tabular}{|c|c|c|}
\hline Variáveis & $\mathbf{n}$ & $\%$ \\
\hline \multicolumn{3}{|l|}{ Gênero } \\
\hline Feminino & 90 & 41,5 \\
\hline Masculino & 127 & 58,5 \\
\hline \multicolumn{3}{|l|}{ Idade } \\
\hline Menor que 18 anos & 10 & 4,6 \\
\hline Entre 18 e 20 anos & 56 & 25,8 \\
\hline Entre 21 e 30 anos & 101 & 46,5 \\
\hline Entre 31 e 40 anos & 22 & 10,1 \\
\hline Entre 41 e 50 anos & 28 & 12,9 \\
\hline \multicolumn{3}{|l|}{ Estado Civil } \\
\hline Solteiro(a) & 159 & 73,3 \\
\hline Casado(a) & 48 & 22,1 \\
\hline Viúvo(a) & 5 & 2,3 \\
\hline União Estável & 5 & 2,3 \\
\hline \multicolumn{3}{|l|}{ Filhos } \\
\hline Sim & 66 & 30,4 \\
\hline Não & 151 & 69,6 \\
\hline \multicolumn{3}{|l|}{ Renda Familiar } \\
\hline A partir de 1 salário mínimo & 35 & 16,1 \\
\hline 2 salários mínimos & 51 & 23,5 \\
\hline 3 salários mínimos & 61 & 28,1 \\
\hline 4 salários mínimos & 15 & 6,9 \\
\hline 5 salários mínimos & 15 & 6,9 \\
\hline Mais de 5 salários mínimos & 40 & 18,4 \\
\hline Total & 217 & 100 \\
\hline
\end{tabular}

Fonte: Elaboração própria.

O público universitário foi selecionado para participar do estudo, pois, segundo Batista (2005), este é o conjunto de pessoas que tem maior interesse no turismo cultural, por constituírem um conjunto de pessoas com características homogêneas que buscam escalas superiores de satisfação, após atenderem suas necessidades mais elementares. Comumente são pessoas que compreendem outra língua, além da sua nativa, e procuram melhorias qualitativas em educação, lazer e, com as viagens culturais, obtém um tipo de status social, especialmente pela dificuldade de acesso, muitas vezes econômica, a esta modalidade turística.

Como o nível de escolaridade foi o mesmo, os outros dados socioeconômicos investigados foram o estado civil, a renda familiar e se os respondentes possuíam ou não filhos. Em sua maioria, o público de respondentes era formado por pessoas solteiras $(73,3 \%)$ e sem filhos $(69,6 \%)$. Em relação à renda familiar, houve proximidade de duas marcações de resposta, as opções 2 e 3 salários mínimos somadas correspondem a 51,6\% do total e, caso somadas aquelas pessoas que marcaram que menos de 1 salário mínimo, compõem 67,7\% da amostra, o que demonstram o médio a baixo poder econômico deste público. 0 salário mínimo brasileiro em janeiro de 2014 foi atualizado para o valor de $\mathrm{R} \$ 724,00$ (setecentos e vinte e quatro reais) e, convertidos a outras moedas, equivalem a aproximadamente EUR 239 (duzentos e trinta e nove euros) e USD 326 (trezentos e vinte e seis dólares) - dados de conversão atualizados em 27 de maio de 2014.

\subsection{Análises univariadas}

Após montar um perfil socioeconômico dos respondentes, o questionário indicava afirmações referentes a motivação para a visita à cidade, satisfação em relação ao passeio turístico e aos serviços prestados, imagem da cidade e do parque, fontes de informação sobre as atrações turísticas e 
intenções de comportamento futuro relacionadas à possibilidade de visitar novamente o local. Cada afirmação era seguida por colunas de resposta em escala Likert, que variavam de "Discordo Totalmente", com nota "1", para "Concordo Totalmente" com nota " 5 " de avaliação. Desta forma, após análises das médias de cada uma das afirmações, elas foram divididas em duas colunas para fins de interpretação neste estudo, postas em ordem crescente, as médias altas foram aquelas que alcançaram resultados acima de 4 e médias baixas aquelas que estavam abaixo deste número. As informações são apresentadas a seguir, seccionadas pelas variáveis conforme foram apresentadas no instrumento de coleta de dados.

\subsubsection{Motivação}

O primeiro conjunto de afirmações analisado, apresentado na Tabela 2, é aquele que compunha o grupo da variável de motivação para visitar a cidade. Os respondentes foram questionados sobre que aspectos mais levavam em conta para optar por esse destino turístico. As afirmações iniciais não obtiveram avaliações positivas, principalmente o tópico "viajar para não fazer nada", que obteve a menor nota de avaliação. As viagens possuíam algum interesse e, conforme dados da tabela dois, não eram intuitos de conhecer pessoas, redescobrir-se, gastronomia diversificada, visitar locais familiares ou visitar amigos e parentes, estar junto da família, ficar longe das exigências de casa, sentir-se seguro e protegido e a limpeza. Todas essas afirmações não foram avaliadas com notas altas. Além destas, algumas receberam notas um pouco maiores, que foram os tópicos encontrar emoções e excitação, sentir-se em casa longe de casa, experimentar novos estilos de vida, restaurantes baratos, culturas diferentes e cidade histórica antiga.

\begin{tabular}{|l|c|c|}
\multicolumn{3}{|c|}{ Tabela 2 São Raimundo Nonato } \\
\multicolumn{1}{|c|}{ Variáveis } & $\begin{array}{c}\text { Médias } \\
\text { Altas }\end{array}$ & $\begin{array}{c}\text { Médias } \\
\text { Baixas }\end{array}$ \\
\hline Não fazer nada & & 1,414 \\
\hline Sentir-me seguro e protegido & & 2,037 \\
\hline Estar junto da família & & 2,244 \\
\hline Redescobrir a mim mesmo & & 2,304 \\
\hline Visitar amigos e parentes & & 2,313 \\
\hline Ficar longe das exigências de casa & & 2,410 \\
\hline Visitar locais familiares & & 2,553 \\
\hline Experimentar gastronomia diferente & & 2,709 \\
\hline Limpeza & & 2,843 \\
\hline Segurança pessoal & & 2,899 \\
\hline Conhecer pessoas & & 3,945 \\
\hline Experimentar novos estilos de vida & & 3,069 \\
\hline Encontrar emoções e excitação & & 3,124 \\
\hline Restaurantes baratos & & 3,179 \\
\hline Culturas diferentes & & 3,230 \\
\hline Sentir-me em casa longe de casa & & 3,309 \\
\hline Cidade histórica antiga & & 3,502 \\
\hline Clima de confiança & & 3,935 \\
\hline Variedade de atividades para ver & 4,511 & \\
\hline Visitar o máximo possível & 4,617 & \\
\hline Cenários deslumbrantes & 4,649 & \\
\hline & Fon & \\
\hline
\end{tabular}

Fonte: Elaboração própria.

As maiores motivações para conhecer a cidade foram: a possibilidade de visitar o local ao máximo possível, a variedade de atividades para ver e os cenários deslumbrantes. Essas respostas permitem associar os interesses de visita ao Parque Nacional da Serra da Capivara às inúmeras possibilidades de paisagens e sítios arqueológicos que o local dispõe. 0 conhecimento prévio destas informações pode ser um fator de atratividade turística, especialmente na internet (Sousa, 2014), ao tempo que faltam ações que possibilitem o entretenimento daqueles que pretendem visitar o local, o que pode justificar as médias baixas para a maioria dessas afirmações (Aguiar \& Carvalho, 2012).

\subsubsection{Satisfação}

No que tange a satisfação dos visitantes, com variáveis apresentadas na Tabela 3, os tópicos mais bem avaliados foram: as paisagens bonitas, a cidade tranquila, as muitas atrações turísticas e o estilo de vida agradável. Esses são aspectos aparentemente intangíveis que são evidenciados pelo próprio cenário. As notas das avaliações foram menores nos aspectos tangíveis e de serviços oferecidos pela cidade como a limpeza e organização da cidade, as atividades culturais, as possibilidades de interações com outros turistas, a facilidade de acesso, as informações sobre a cidade, a gastronomia e a relação entre custo e benefício dos serviços oferecidos.

Tabela 3 - Variáveis de satisfação em relação à visita à cidade de São Raimundo Nonato

\begin{tabular}{|l|l|l|}
\hline \multicolumn{1}{|c|}{ Variáveis } & \multicolumn{1}{|c|}{$\begin{array}{c}\text { Médias } \\
\text { Altas }\end{array}$} & $\begin{array}{c}\text { Médias } \\
\text { Baixas }\end{array}$ \\
\hline Interações com outros turistas & & 3,051 \\
\hline Fáceis acessos & & 3,249 \\
\hline $\begin{array}{l}\text { Cidade limpa e organizada } \\
\text { Fáceis informações sobre São }\end{array}$ & & 3,373 \\
\hline $\begin{array}{l}\text { Raimundo Nonato } \\
\text { Preços qualidade } \\
\text { (custo/benefício) }\end{array}$ & & 3,433 \\
\hline $\begin{array}{l}\text { Várias atividades culturais } \\
\text { Ótima gastronomia }\end{array}$ & & 3,793 \\
\hline Clima agradável & & 3,829 \\
\hline Estilo de vida local agradável & 4,088 & 3,939 \\
\hline Muitas atrações turísticas & 4,387 & \\
\hline Cidade tranquila & 4,488 & \\
\hline Paisagens bonitas & 4,839 & \\
\hline
\end{tabular}

Fonte: Elaboração própria.

Sobre os serviços prestados na cidade, Pessis \& Guidon (2007) informam que a última década foi um período de evolução positiva neste setor. As melhorias estão associadas à acomodação (hotelaria) e o acesso à cidade e ao parque, o que beneficiou a população local e o desenvolvimento regional, atraindo mais turistas. Tais práticas apoiaram a demanda local por alimentação e transporte de qualidade, além do estimulo à produção de souvernirs para venda aos visitantes. Para Aguiar \& Carvalho (2012) os serviços da cidade são precários e não atendem as demandas, apesar do seu crescente desenvolvimento, o que sinaliza uma necessidade ampliação e melhoria.

\subsubsection{Imagem}

De modo geral e em comparação às outras variáveis em estudo, a imagem foi o conjunto avaliado com as notas mais altas, apenas as atividades culturais oferecidas obtiveram avaliações mais baixas. A imagem é um dos principais pontos de atratividade turística (Calvo-Mora et al., 2011) e determina o posicionamento competitivo. Neste ponto, o 
Parque Nacional da Serra da Capivara é apresenta índices que demonstram sua posição perante seus visitantes, tal como apresentado na Tabela 4, e o que é naturalmente oferecido pela paisagem obteve altas médias de avaliação.

Tabela 4 - Variáveis de imagem da cidade de São Raimundo Nonato

\begin{tabular}{|l|c|c|}
\hline \multicolumn{1}{|c|}{ Variáveis } & Médias Altas & Médias Baixas \\
\hline $\begin{array}{l}\text { Muitas atrações culturais } \\
\text { Atividades culturais } \\
\text { interessantes }\end{array}$ & & 3,659 \\
\hline $\begin{array}{l}\text { Clima agradável } \\
\text { Variedade de locais para } \\
\text { descansar }\end{array}$ & 4,018 & 3,792 \\
\hline $\begin{array}{l}\text { Lugar tranquilo } \\
\text { Povo hospitaleiro }\end{array}$ & 4,142 & \\
\hline Variedade de fauna e flora & 4,578 & \\
\hline $\begin{array}{l}\text { Muitas oportunidades para } \\
\text { os aventureiros }\end{array}$ & 4,728 & \\
\hline Paisagens agradáveis & 4,765 & \\
\hline
\end{tabular}

Fonte: Elaboração própria.

Como as atrações culturais e as atividades de mesmo fim devem ser organizadas por equipe própria para sua execução, evidencia-se um problema percebido pelos visitantes enquanto não consideraram este um ponto forte da atividade turística.

\subsubsection{Fontes de informação}

O conjunto de afirmações que compunha a variável "fontes de informação" foi todo avaliado com médias baixas, tal como apresentado na Tabela 5. A maior fonte de informação para o público respondente foi a internet, por meio de fóruns ou sítios eletrônicos. Em seguida estavam os amigos e a família e a publicidade na televisão ou no rádio. Os resultados apresentados na tabela 5 demonstram que há fragilidade de divulgação dos roteiros turísticos que levam visitantes à cidade de São Raimundo Nonato. Para Sousa (2014) aquele que possuir melhores estratégias de divulgação garantem maior participação e atratividade turística e, assim, maiores vantagens na opção de escolha do visitante.

Tabela 5 - Variáveis de fontes de informação sobre a cidade de São Raimundo Nonato

\begin{tabular}{|l|l|l|}
\hline \multicolumn{1}{|c|}{ Variáveis } & $\begin{array}{c}\text { Médias } \\
\text { Altas }\end{array}$ & $\begin{array}{c}\text { Médias } \\
\text { Baixas }\end{array}$ \\
\hline Panfletos & & 2,101 \\
\hline Postos de turismo & & 2,576 \\
\hline $\begin{array}{l}\text { Agências de viagem / Livros de } \\
\text { viagem }\end{array}$ & 2,696 \\
\hline $\begin{array}{l}\text { Experiências de viagens passadas } \\
\text { Staff do hotel / restaurante / } \\
\text { empresa de aluguel de carros }\end{array}$ & 2,921 \\
\hline Publicidade na TV / Rádio & & 2,926 \\
\hline $\begin{array}{l}\text { Residentes que conheci } \\
\text { encontrei }\end{array}$ & & 3,212 \\
\hline Amigos e família & 3,516 \\
\hline Fóruns (ou sites) na internet & & 3,543 \\
\hline
\end{tabular}

Fonte: Elaboração própria.

Pessis \& Guidon (2007) afirmam que é necessário divulgar em campanhas publicitárias formas de conscientizar a população local e não-local sobre a relevância do contexto educativo, ambiental e cultural do Parque Nacional da Serra da Capivara, também como um meio de evitar a degradação da área. No contexto das informações mais acessíveis esta necessidade permanece latente. Atualmente, a partir de um instrumento de informática conectado à internet, o consumidor tem todas as informações quantas forem possíveis a respeito de um local e, às vezes, possui mais conhecimento sobre as atrações turísticas que os próprios residentes do lugar (Richards, 2010).

\subsubsection{Intenções de comportamento futuro}

Quando questionados sobre o que poderia leva-los a visitar novamente a cidade, os respondentes afirmaram que suas principais intenções de comportamento futuro eram garantidas pela boa experiência que tiveram enquanto estavam hospedados no local e, em caso de nova oportunidade, pretendiam repetir o passeio. A Tabela 6 apresenta os resultados das análises destas variáveis, com a avaliação mais baixa na variável que dizia ser superior o serviço oferecido pela cidade quando comparado a outros locais, seguida da cidade como primeira opção no próximo destino turístico.

Tabela 6 - Variáveis de intenção de comportamento futuro em relação a visitas à cidade de São Raimundo Nonato

Variáveis
$\begin{aligned} & \text { A cidade fornece qualidade de } \\ & \text { serviço superior quando } \\ & \text { comparado a outros locais que } \\ & \text { visito. }\end{aligned}$

Fonte: Elaboração própria.

Para Calvo-Mora et al. (2011) as possibilidades de melhoria da atratividade turísticas de um lugar perpassam um conjunto de estratégias em âmbitos públicos e privados, relacionadas ao posicionamento turístico, a conscientização dos residentes destas atividades, o bom emprego da riqueza cultural, patrimonial e social, bem como a melhoria das infraestruturas para recepcionar o visitante, como da gestão do turismo.

\subsection{Análise de regressão linear}

Para os procedimentos de análise de regressão linear foram propostos cinco cenários diferentes associando as variáveis entre si. Este modelo de teste foi proposto por Ferreira (2013) e buscava verificar quais eram as variáveis que possuíam efeito significativo nas demais. Em sua análise, as variáveis satisfação e motivação foram aquelas com maior poder de explicação no teste, as únicas com valores satisfatórios. Na proposição deste estudo, os resultados 
diferem daqueles encontrados pela autora, uma das contribuições teóricas deste trabalho. Os cenários dos testes de regressão, apresentados na Tabela 7 , foram os seguintes:

Cenário 1: A motivação tem efeito significativo nas variáveis imagem, satisfação, comportamento futuro e fontes de informação?

Cenário 2: A imagem tem efeito significativo nas variáveis motivação, satisfação, comportamento futuro e fontes de informação?
Cenário 3: A satisfação tem efeito significativo nas variáveis imagem, motivação, comportamento futuro e fontes de informação?

Cenário 4: As fontes de informação têm efeito significativo nas variáveis imagem, satisfação, comportamento futuro e motivação?

Cenário 5: 0 comportamento futuro tem efeito significativo nas variáveis imagem, satisfação, motivação e fontes de informação?

Tabela 7 - Apresentação dos testes de regressão linear

\begin{tabular}{|c|c|c|c|c|c|}
\hline $\begin{array}{c}\text { Variável } \\
\text { dependente }\end{array}$ & $\begin{array}{c}\text { Variáveis } \\
\text { independentes }\end{array}$ & P-value & $\begin{array}{c}\text { Coeficiente de } \\
\text { determinação }\left(r^{2}\right)\end{array}$ & $\begin{array}{l}\text { Coeficiente de } \\
\text { correlação (r) }\end{array}$ & $\begin{array}{l}\text { P-value } \\
\text { Teste F }\end{array}$ \\
\hline Motivação & $\begin{array}{l}\text { Imagem } \\
\text { Satisfação } \\
\text { Informação } \\
\text { Futuro }\end{array}$ & $\begin{array}{l}0,000 \\
0,000 \\
0,000 \\
0,010\end{array}$ & 0,371 & 0,609 & 0,000 \\
\hline Imagem & $\begin{array}{c}\text { Motivação } \\
\text { Satisfação } \\
\text { Informação } \\
\text { Futuro }\end{array}$ & $\begin{array}{l}0,000 \\
0,000 \\
0,077 \\
0,000\end{array}$ & 0,567 & 0,753 & 0,000 \\
\hline Satisfação & $\begin{array}{l}\text { Imagem } \\
\text { Motivação } \\
\text { Informação } \\
\text { Futuro }\end{array}$ & $\begin{array}{l}0,000 \\
0,000 \\
0,021 \\
0,000\end{array}$ & 0,620 & 0,787 & 0,000 \\
\hline $\begin{array}{l}\text { Fontes de } \\
\text { Informação }\end{array}$ & $\begin{array}{c}\text { Motivação } \\
\text { Satisfação } \\
\text { Imagem } \\
\text { Futuro }\end{array}$ & $\begin{array}{l}0,000 \\
0,021 \\
0,077 \\
0,268\end{array}$ & 0,337 & 0,580 & 0,000 \\
\hline $\begin{array}{l}\text { Comportamento } \\
\text { Futuro }\end{array}$ & $\begin{array}{l}\text { Motivação } \\
\text { Satisfação } \\
\text { Informação } \\
\text { Imagem }\end{array}$ & $\begin{array}{l}0,010 \\
0,000 \\
0,268 \\
0,000\end{array}$ & 0,518 & 0,719 & 0,000 \\
\hline
\end{tabular}

Fonte: Elaboração a partir de dados de pesquisa (2014), estrutura adaptada de Ferreira (2013).

Pela observação dos coeficientes de determinação $(R$ Square), pode-se afirmar que $62 \%$ da variação da satisfação são explicadas pelo modelo de regressão do terceiro cenário, sendo médio o poder de explicação do modelo e, para todos os outros cenários, os resultados têm um poder de explicação baixo ou ruim conforme interpretação dos coeficientes de determinação $\left(r^{2}\right)$, para $0,6 \leq r^{2} \leq 0,8$ (Martins \& Domingues, 2011). Para o coeficiente de correlação (r), o cenário " 3 " também é o que apresenta maior associação linear entre as variáveis de estudo, pois seu valor é tanto melhor quanto mais se aproxima do valor de 1. Outros cenários também apresentaram linearidade média entre suas variáveis, sendo eles os cenários " 2 " e “5”.

\section{Conclusões}

Estes resultados permitem concluir que o modelo de regressão linear possui médio poder de explicação para o cenário que propõe que a satisfação tem efeito significativo nas variáveis imagem, motivação, comportamento futuro e fontes de informação, sendo ela explicada pelas demais em $62 \%$. Os resultados são suportados pelo valor da análise dos $p$-values do teste de regressão, pois assume o valor de 0,000 e, quando comparado ao nível de significância de 0,05 conclui-se que se tem influência significativa. Ao analisar o teste F, recai-se na mesma conclusão.

Além dos resultados do teste de regressão, também são possíveis conclusões a respeito do comportamento turístico do visitante de São Raimundo Nonato. Suas principais motivações para realizar o passeio turístico à cidade são a máxima possibilidade de visita, a variedade de atividades para ver e os cenários deslumbrantes proporcionados pelo local. A satisfação da atividade turística foi observada especialmente nas paisagens bonitas, nas muitas atrações turísticas, na cidade tranquila e no estilo de vida local agradável.

Em relação à imagem que possuem da cidade após visitá-la, os turistas afirmaram que aquilo que mais agradou visualmente foi: a variedade de fauna e flora, as paisagens agradáveis, o clima agradável, o povo local hospitaleiro, as muitas oportunidades para os aventureiros (dentre as quais podem ser citadas as trilhas ecológicas e as visitas aos sítios arqueológicos mais distantes), o lugar tranquilo e as variedades de locais para descansar. Em associação a estas práticas culturais podem ser evidentes os conceitos de ecoturismo, que utilizam práticas sustentáveis, com mínima degradação ambiental, onde a própria paisagem é o atrativo.

Os resultados empíricos sobre as fontes de informação apontam um cenário de fragilidade na divulgação das atrações turísticas sobre a cidade e o parque. A fonte que apresenta melhores resultados é a internet, apesar dessa também não ter sido bem avaliada. As intenções de comportamento futuro residem na boa experiência que os visitantes tiveram, apesar desta não ser a primeira opção quando pensam em uma nova viagem e os serviços prestados no local não serem superiores a outros que já experimentaram. 
As principais contribuições deste estudo são os resultados diversos àqueles alcançados por Ferreira (2013) quando aplicou a mesma escala em uma amostra de visitantes culturais, evidenciando que não são as mesmas variáveis que explicam o comportamento do turista em diferentes contextos. Para futuros estudos, sugerem-se a aplicação da mesma escala em um público mais heterogêneo em relação à sua escolaridade e faixa etária, bem como pesquisas de mesmo interesse em outros contextos turísticos. Ainda como uma perspectiva futura de análise, a cidade de São Raimundo Nonato possui acesso a práticas de Ecoturismo, que foram superficialmente evidenciadas nesta análise, o que abre espaço para estudos que intentem investigar esta dimensão sustentável das atividades turísticas.

\section{Referências}

Aguiar, E.P.S., \& Carvalho, S.M.S. (2012). Turistas de São Raimundo Nonato - PI: perfil e grau de satisfação quanto aos serviços de alimentação. Turismo em Análise, 23(3), 600-622.

Batista, C.M. (2005). Memória e identidade: aspectos relevantes para o desenvolvimento do turismo cultural. Caderno Virtual do Turismo, 5(3), 27-33.

Batista, M.G., Couto, J.P., Botelho, D. \& Faias, C. (2014). Tourist satisfaction and loyalty in the hotel business: an application to the island of São Miguel, Azores. Tourism \& Management Studies, 10(1), 16-23.

Brasil. (2006). Projeto de desenvolvimento sustentável do turismo da região do Parque Nacional Serra da Capivara. Brasília: Ministério do Turismo.

Carvalho, S.M.S. (2012). Acessibilidade do turismo no Parque Nacional da Serra da Capivara. Turismo em Análise, 23(2), 437-463.

Calvo-Mora, A., Berbel-Pineda, J.M., Periáñez, R. \& Suárez, E.M. (2011). Determining factors of a city's tourism attractiveness. Tourism \& Management Studies, 7, 9-23.

Ferreira, A.M.M. (2013). As motivações e satisfação dos turistas presentes em Guimarães CEC 2012. (Master dissertation, Instituto Politécnico de Viseu, 2013) Retrieved from http://hdl.handle.net/10400.19/2048

FUMDHAM. (2014). Fundação Museu do Homem Americano (Institutional Website). Parque Nacional Serra da Capivara. Retrieved from http://www.fumdham.org.br

Kitterlin, M. \& Yoo, M. (2014). Festival motivation and loyalty factors. Tourism \& Management Studies, 10(1), 119-126.

Kuvan, Y., \& Perran, A. (2005). Resident's attitudes toward general and forest-related impacts of tourism: the case of Belek, Antalya. Tourism Management, 26(5), 691-706.

Martins, G.A., \& Domingues, O. (2011). Estatística geral e aplicada. São Paulo: Atlas.

Mesquita, R. F. D., Sousa, M. B. D., Martins, T. B., \& Matos, F. R. N. (2014). Óbices metodológicos da prática de pesquisa nas ciências administrativas. Revista Pensamento Contemporâneo em Administração,8(1), 50-65.

Moletta, V.F. (1998). Turismo Cultural. Porto Alegre: SEBRAE/RS.

Moreno, M.R., Molina, C.M. \& Moreno, R.R. (2013). Satisfacción, lealtad y colectivismo em destinos culturales. Tourism \& Management Studies, 9(2), 44-49.

Oliveira, E.E., Silva, J., \& Moreira, S.I. (2009). Desenvolvimento cultural e turístico: uma relação passível de sustentabilidade? Observatório de Inovação do Turismo, 4(4), 1-17.

Oliveira Filho, R.C., \& Monteiro, M.S.L. (2009). Ecoturismo no Parque Nacional Serra da Capivara: trata-se de uma prática sustentável. Turismo em Análise, 20(2), 230-250.

Pessis, A., \& Guidon, N. (2007). Serra da Capivara National Park, Brazil: cultural heritage and society. World Archaeology, 39(3), 406-416.

Pérez, X.P. (2009). Turismo cultural: uma visão antropológica. Tenerife: ACA y PASOS, RTPC.
Richards, G. (2010). Tourism development trajectories - from culture to creativity? Tourism \& Management Studies, 6, 9-15.

Rodríguez, J.R.M. \& Abdul-Jalbar, B. (2012). Turismo cultural y planificación Del viaje: um estudio de caso. Tourism \& Management Studies, 8, 41-47.

Sousa, C. (2014). A influência da internet na escolha de um destino turístico. Cogitur, Journal $f$ Tourism Studies, O(5), 143-156. Retrieved from http://revistas.ulusofona.pt/index.php/jts/article/view/4430

Tiago, M.T.B. \& Tiago, F.G.B. (2013). The influence of teenagers on a family-s vacation choices. Tourism \& Management Studies, 9(1), 28-34.

Submetido: 06.05.2014

Aceite: 25.11 .2014 